\title{
La Arqueta de las Bienaventuranzas: fuentes iconográficas
}

Ma Concepción Cosmen Alonso

RESUMEN. La llamada Arqueta de las Bienaventuranzas se expone en el Museo Arqueológico de Madrid, pero procede de San Isidoro de León, y, posiblemente, formó parte de la donación de 1063 hecha por los reyes Fernando I y Sancha. Desgraciadamente, hoy es una pieza recompuesta, despojada de toda la decoración de orfebrería complementaria, donde destacan siete plaquetas con las inscripciones de otras tantas bienaventuranzas, junto con figuras de ángeles y santos emparejados bajo arquitecturas. Un tema tan abstracto puede explicarse a través de las fuentes patrísticas altomedievales que se seleccionan en los leccionarios y homiliarios litúrgicos o se conservan más desarrolladas en algunos textos, muy conocidos, de las bibliotecas monásticas y señoriales del occidente europeo. El asunto desarrollado en la obra artística es muy apropiado para un relicario.

Palabras clave: arqueta, plaquetas ebúrneas, bienaventuranzas, ángeles, santos, Jerusalén celeste, homiliarios, fuentes patrísticas, relicario.

RESUME. Le coffret des Béatitudes est conservé au Mussée archéologique de Madrid, mais il vient de Saint Isidore de León, peut-être de la donation de 1063 des rois Fernando I et Sancha. Il a été malheureusement dépouillé de tout son décor d'orfévrerie complémentaire. Il a été refaite avec la réunion de plusieurs plaques en ivoire dont sept portent les inscriptions des béatitudes avec de paires d'saints et des anges sous des architectures. Nous pouvons nous expliquer les images d'un sujet aussi abstrait si nous connaissons quelques textes patristiques du haut Moyen-Âge qui font partie des homéliaires et lectionnaires liturgiques, ainsi que d'autres oeuvres de grands écrivains chrétiens conservés dans les bibliothèques des centres monastiques ou seigneurials européens. L'idée développée sur l'oeuvre artistique est bien convenable à un châsse.

Mots clé: coffret, plaques en ivoire, béatitudes, anges, saints, Jérusalem céleste,homéliaires, sources patristiques, châsse.

El rico tesoro sagrado que poseyó la Real Colegiata de San Isidoro parece que fue producto, en gran medida, de la munificencia de los soberanos leoneses. Posiblemente esta pieza formó parte de aquella espléndida donación, hecha en 1063 por los reyes Fernando I y Sancha, a la iglesia de San Juan Bautista y San Pelayo de León con motivo de la llegada de los restos del obis- po hispalense ${ }^{1}$. La arqueta, tal vez recompuesta en el siglo XIX tras el pillaje sufrido por la Colegiata durante la invasión napoleónica, es un prisma de madera que se recubre -en tres de sus lados- con siete placas ebúrneas, donde se tallaron, bajo arcos

-

${ }^{1}$ Véase, A. FRANCO MATA, "El arte medieval cristiano leonés en el Museo Arqueológico Nacional", Tierras de León, 71 ( 1988) 35 y E. MARTín LóPEZ, Patrimonio cultural de San Isidoro de León.I/1 Documentos de los siglos X-XIII, León, 1995, pp. 26-29. 
con inscripciones alusivas al Sermón de la Montaña (Mateo 5, 3-10), parejas de bienaventurados y ángeles (lámina 1)². La cuarta cara externa presenta un inconexo conjunto de siete fragmentos tallados con motivos epigráficos ("Ismail hijo de AI-Mamun doblemente famoso" y" A su dueño doblemente feliz"), fitomorfos y zoomorfos de filiación islámica ${ }^{3}$. La importancia de la obra estriba tanto en la forma plástica de las siete piezas ebúrneas que forman conjunto como en el asunto que en ellas se trata. En cada una de las placas se representa a un ángel que parece conversar con un personaje masculino, nimbado o no, ambos se colocan bajo un arco de medio punto apoyado en columnas torsas de capiteles vegetales, en cuya rosca se inscribieron los textos relativos a las bienaventuranzas. Sobre las arquerías se diseñaron construcciones de uno o varios pisos con cubiertas de pendientes lisas o abovedadas y algún remate almenado (lámina 1).

Por otra parte, es muy posible que, además de con marfil, la caja estuviese recubierta de metales preciosos que desaparecieron en el episodio bélico anteriormente mencionado ${ }^{4}$.

Desde el punto de vista artístico se han puesto en relación estas plaquetas con la de Cristo en Majestad del Museo del

\footnotetext{
2 La caja, en 1869, era un relicario que poseía las representaciones de las bienaventuranzas en su "respaldo", tal como se describió en, J. PÉREZ LlAMAZARES, Historia de la Real Colegiata de San Isidoro de León, León, 1927 (1982), p. 215. Además, A. GolDSCHMIDT, Die Elfenbeinskulpturen aus der romanischen zeit, IX-XIII, Jahrhundert, Berlín, 1926(1975), t. IV, p. 29; J. A. HARRIS, "Beatitudes Casket", The Art of medieval Spain, $a . d$. 500-1200, Nueva York, 1993, p. 253 y A. FRANCO MATA, "El tesoro de San Isidoro y la monarquía leonesa", Boletín del Museo Arqueológico Nacional, IX, 1 y 2 (1991) 54.

${ }^{3}$ M. Estella MARCOS, La escultura de marfil en España: románica y gótica, Madrid, 1984, p. 29.

${ }^{4}$ J. FERRANDIS, Marfiles y azabaches españoles, Barcelona, 1928 , pp. 151-151.
}

Louvre, posiblemente también de procedencia leonesa y del siglo $\mathrm{XI}$, pues existe en todas ellas un tratamiento de las figuras, entre caligráfico y tendente a cierto volumen, con detalles anatómicos conseguidos y movimientos contenidos, amén de las incrustaciones de azabache en los ojos ${ }^{5}$.

En el arte cristiano medieval, que hoy conocemos, no es nada común la representación del asunto que va a ocuparnos, y, sobre todo, de forma tan pormenorizada como aquí aparece tratado. En la arqueta, se debieron mostrar individualmente cada una de las ocho bienaventuranzas, tal como fueron relatadas en el Evangelio de San Mateo 5, 3-10, aunque desgraciadamente sólo se conserven siete de las ocho representaciones que conformarían el ciclo completo ${ }^{6}$.

Por lo tanto, nos hallamos ante un ejemplo artístico excepcional, de origen plástico no conocido, de momento. Para su interpretación ha sido fundamental el paso dado por la investigadora Julie A. Harris, quien -de forma muy clara- hizo una explicación del tema en relación con la liturgia hispana antigua, en la que existen antífonas, dentro de los servicios religiosos, donde, en honor a los santos, se entonan varias de las bienaventuranzas bíblicas ${ }^{7}$.

${ }^{5}$ J. BOUSQUET, "Les ivoires espagnols du milieu du XI siècle: leur position historique et artistique", Cahiers de Saint Michel de Cuxa, 10 (1979) 48; P. LASKO, Arte sacro 800-1200, Madrid, 1999(1972), p. 264; D. PERRIER, "Die Spanische KleinKunst des 11. Jahrhunderts", Aachener Kunstblätter, 52 (1984) 71; A. FRANCO MATA, "La eboraria de los reinos hispánicos durante los siglos XI y XII", Codex Aqvilarensis, 13 (1990) 151.

${ }^{6}$ Véase para el origen y expansión del tema iconográfico, L. RÉAU, Iconografía del arte cristiano, Barcelona, 1999 (1958), t. 1, vol. 2, pp. 331-332 y G. SCHILLER, Iconography of Christian Art, Londres, 1972(1968), vol. 1 , pp. 156-157.

7 J. A. HARRIS, "The Beatitudes Casket in Madrid's Museo Arqueológico: Its Iconography in Context", Zeitschrift für Kunstgeschichte, 53 (1990) 138-139. 
Intentando seguir esta vía abierta, hemos ahondado en el estudio de textos litúrgicos medievales, distintos del Antifonario, con el fin de completar el porqué de las imágenes ebúrneas.

Hemos buscado, en primer lugar, otros momentos en los que las lecturas referentes al Sermón de la Montaña estaban presentes en los círculos eclesiásticos alto y pleno medievales. Con ello quisimos ampliar el ámbito de incidencia de dichos escritos, no quedarnos sólo con los leídos en el trascurso de la misa, sino también en los oficios del clero y en los refectorios. Así, se han explorado los fragmentos literarios que eran objeto de estudio alrededor de los pasajes de San Mateo señalados, o de la versión mas sintética de San Lucas 6, 20-22. En general, se trataba de exposiciones teóricas, más o menos desarrolladas $\mathrm{y}$, sobre todo, de sermones y homilías, realizados por destacadas figuras de la Iglesia altomedieval. Estos personajes hicieron una labor de exégesis que será aceptada, sin muchas variaciones, durante toda la Edad Media. De sus obras, mediante resúmenes convenientemente seleccionados, se estudiaban ciertos capítulos que servían de fuente de conocimiento y reflexión para la celebración de la festividad correspondiente del calendario litúrgico ${ }^{8}$.

Esta primera etapa de la investigación nos condujo a otras que se vieron enriquecidas con la revisión de nuevas obras escritas, pero, dependientes ideológicamente de las anteriores; fuentes donde el asunto de los bienaventurados se enlaza con la existencia de los ángeles o se encauza alrededor de la interpretación de la vida de los santos, de los justos y de los mártires. Por lo tanto, elementos que sirven para

8 R. GREgOIRE, Les Homéliaires liturgiques médiévaux, Spoleto, 1980, pp. 17-37. comprender las imágenes de las figuras que se tallan en la arqueta.

Por otra parte, la aparición de arquitecturas, que podrían ser una alusión a una ciudad ideal -la Jerusalén celeste- no es más que un intento de completar de forma figurada algunos razonamientos de los aludidos escritos ${ }^{9}$. Es decir, toda la representación plástica se podría explicar siguiendo las ideas expuestas por ciertos autores cristianos anteriores al siglo $\mathrm{XI}$, en el que supuestamente se realizó la obra. Pero, además, los citados pensamientos parecen tener una fuente primigenia y común que los inspira y acerca entre sí, se trata de la obra de San Agustín De Sermone Domini in Monte, $\mathrm{y}$, junto a ella, un grupo de sus homilías sobre la vida de los bienaventurados, donde incide y desarrolla ideas ya esbozadas en la pieza anterior. Por otra parte, el mismo escritor y sus seguidores más próximos, como Cesáreo de Arles, van a divulgar de forma muy exitosa las ideas del primero sobre La Ciudad de Dios, y de algún modo, esta corriente de pensamiento le llega al mentor de la arqueta leonesa.

Las ideas agustinianas fueron retomadas y desarrolladas, incluso haciéndolas más accesibles a veces, por grandes figuras de la Iglesia, como por ejemplo San Gregorio y San León Magno, San Isidoro de Sevilla o Beda el Venerable ${ }^{10}$. De toda esta producción literaria es de donde se nutrieron las colecciones de homilías medievales, que, no sólo conocían los clérigos, sino también los laicos. Tanto en la corte de Carlomagno como en la del conde Évrard de Friuli se

\footnotetext{
${ }^{9}$ Sin que se cite texto teórico alguno ya fueron interpretadas las construcciones como de la Jerusalén celeste por J. BOUSQUET, Ob. cit., p. 48.

10 Obras de San Gregorio Magno, Madrid, 1958, p. 83; San León Magno. Homilías sobre el año litúrgico, Madrid, 1969, p.36; M. C. DÍAZ Y DÍAZ, De Isidoro al siglo XI. Ocho estudios sobre la vida literaria peninsular, Barcelona, 1976, pp. 32-33.
} 
poseían colecciones de los sermones del obispo de Hipona y La Ciudad de Dios era una de los libros más leídos por el emperador ${ }^{11}$. Por otra parte, uno de los leccionarios litúrgicos más copiados en la Edad Media fue el de Pablo Diácono, realizado entorno al año 800, por orden del monarca citado, y donde el santo de Hipona es una autoridad repetidamente utilizada, así como algunas de las obras de los seguidores que hemos mencionado más arriba ${ }^{12}$.

Para la Península Ibérica, durante la Alta Edad Media, la autoridad de San Agustín era irrefutable, así uno de los textos más renombrados en la época visigoda fue el referido a la citada ciudad del santo obispo $^{13}$. No obstante, y a pesar de las circunstancias históricas, parece que el sur vivió más tiempo este influjo agustiniano que regresará al norte con los grupos de emigrados, sobre todo, en el siglo X. De este modo, en los monasterios gallegos de Celanova o Samos, en el leonés de Abellar y en las sedes episcopales de Oviedo y León, los manuscritos de De Trinitate, La Ciudad de Dios o algún Sermonario del mismo autor vuelven a figurar en las bibliotecas; incluso, ya en el siglo XI, en Oña, también se rastrean sus obras ${ }^{14}$.

El uso de textos semejantes en los círculos de la corte sería probable, pero, desgraciadamente son muy escasas las

11 Obras completas de San Agustín, Madrid, 2000 (5a edic.),t XVI, p. 79; P. VerbRAKEN, "La collection de sermons de Saint Agustín De Verbis Domini et Apostoli", Révue Bénédictine, 77 (1967) 41.

${ }^{12}$ R. GRegoIre, Les Homéliaires du Moyen Âge, Roma, 1966, pp. 70-114 y R. GREGOIRE, Homéliaires liturgiques médiévaux, Spoleto, 1980, pp. 423-486.

${ }^{13}$ M. C. DÍAZ Y DÍAZ, Códices visigóticos en la Monarquía Leonesa, León, 1983, p. 47; M. C. DíAZ Y DÍAZ, "San Agustín en la Alta Edad Media española a través de sus manuscritos", Augustinus, XIII (1968) 141-151.

${ }^{14}$ M. C. DÍAZ Y DÍAZ, Códices visigóticos..., pp. 149246. graciadamente son muy escasas las noticias sobre bibliotecas de laicos en este periodo ${ }^{15}$.

En el contexto litúrgico hispano, anterior a la implantación del rito romano, en el que presumiblemente se realizó la arqueta, tenemos con seguridad la conmemoración del día de todos los santos como momento crucial en el que se leía el Sermón de la Montaña siguiendo el evangelio de San Mateo. Así se explicita en el Liber Commicus, que era de uso general en la Península en toda la Alta Edad Media ${ }^{16}$. En dicha efemérides y fechas circundantes del tiempo ordinario, junto a este fragmento evangélico, se hacían otras lecturas, bien en los oficios de maitines, bien en el refectorio, bien a los fieles. En ellas se interpretaba el Sermón de la Montaña a través de homilías y textos patrísticos, tal como lo recogen los homiliarios hispanos ${ }^{17}$.

En la Península, para fechas próximas a la datación de la arqueta, se realizaron leccionarios basados en dos colecciones fundamentales, la de Esmaragdo de Saint

-

${ }^{15}$ Ibidem, pp. 220-227.

${ }^{16}$ Fr. J. PÉrez De Urbel y A. GonZÁlez Y RuizZorRILlA, Liber Commicus, Madrid, 1950-55, pp. 466468.

${ }^{17}$ Para el resto de Europa la cuestión se trata de forma semejante, aunque difieren las fuentes empleadas. En los homiliarios de la Iglesia romana y por supuesto, en la recopilación de Alain de Farfa se escogen fragmentos que no son los específicamente usados por la Iglesia Hispana antigua, pero, por el contrario, la colección de Pablo Diácono, que será muy usada por Cluny y otras órdenes religiosas, sí será incorporada en nuestra liturgia. Para estos asuntos son fundamentales las dos obras de Réginald Grégoire citadas y la de R. ÉTAIX, Homéliaires patristiques latins, París, 1994. Para el caso español, aún falta una obra de conjunto, a pesar del esfuerzo de algunos investigadores por clarificar el tema en las parcelas que les toca estudiar, un ejemplo significativo sería la obra de la doctora Ana Isabel SUÁREZ GONZÁLEZ, Patrimonio cultural de San Isidoro de León. Serie Bibliográfica. Los códicesVI-X. 2,León, 2000. En ella, dos de los manuscritos que se estudian con gran profundidad, el número VIII y el IX, incorporan partes de dos homiliarios hispanos. 
Michael y la de Pablo Diácono. Dichas obras habían sido terminadas al iniciarse el siglo IX y poco tiempo después ya eran conocidas en nuestro país ${ }^{18}$.

Por lo tanto, junto a la perícope evangélica se disponía un cierto número de comentarios que la interpretaban. Lamentablemente, casi todos estos leccionarios hispanos han llegado a nosotros incompletos, pero sabemos que para el día de los Santos se incluían fragmentos fundamentales de los cinco primeros capítulos, del libro primero, del De Sermone Domini in Monte de San Agustín, tal como había sido seleccionado por Esmaragdo ${ }^{19}$.

Esta lectura se rastrea en los códices 1 y 2 de la Catedral de Burgos más, en otros dos, que provienen de Silos y hoy se hallan en la Biblioteca Nacional de París, N. A. L. 2176 y 2177, todas ellas obras del siglo XI; pero además, se mantiene en el manuscrito IX de la Real Colegiata de San Isidoro de León, datable a fines de la duodécima centuria ${ }^{20}$. Por supuesto, estas obras copian modelos anteriores que no conocemos con exactitud.

Por otra parte, contamos también con los textos que se usaron para las lecturas litúrgicas de las fechas del tiempo ordinario próximas a primeros de noviembre, día de todos los santos. En este caso se extrajeron de la recopilación de Pablo Diácono y son fragmentos firmados por San León Magno y Beda el Venerable, sobre las bie-

18 Véase, R. ÉTAIX, Ob.cit., p. 414 y M. C. DÍAZ Y DÍAZ, Códices visigóticos..., p. 203.

${ }^{19}$ El texto de Esmaragdo se encuentra en el tomo 102, columnas 545-546D, de la Patrologiae Latinae de P. Migne y se extrae del de San Agustín, que aparece en la misma obra, tomo 34, columnas 1229-1237. (de ahora en adelante se citará P. L.).

${ }^{20}$ M. C. DÍAZ Y DÍAZ, Códices visigóticos..., pp. 347,348,365 y 366; R. ÉTAIX, Ob. cit., pp. 389, 395, 396 a 400, 408 y 409 y A. I. SUÁREZ, Patrimonio cultural..., pp. $323,396,397,433$ y 434 . naventuranzas, y, junto a ellos, el Sermón 31 de San Agustín sobre el Salmo 125, 5-6, que se puede considerar como precursor de una de las sentencias del Sermón de la Montaña. Vestigios de dichas obras están presentes en los Códices de Burgos y de la Biblioteca de París, que acabamos de citar, pero también en otros manuscritos como el número 1 de Córdoba, del siglo $\mathrm{X}$, o en otro silense, que hoy está en la biblioteca de la Universidad de Reading, ms. Saint George's Guild 2, que se fecha en el siglo XI ${ }^{21}$.

Las fuentes citadas van a proporcionarnos una serie de ideas que conformarán, en parte, la base simbólica sobre la que se sustentan las imágenes de la obra de arte objeto de nuestra atención.

Analizando dichos textos, hemos podido comprobar que San Agustín en su De Sermone Domini in Monte realizó un amplio estudio del capítulo quinto del evangelio de San $\mathrm{Mateo}^{22}$. La obra, que se ha fechado entre los años 393 y 394, se distribuyó en dos libros y en el primero de ellos se encuentran los fragmentos que se reprodujeron en las colecciones mencionadas.

En el capítulo primero de dicho trabajo ya se explica que el Sermón de la Montaña es " un método perfecto de vida cristiana", para a continuación, ir desgranando e interpretando las siete primeras bienaventuranzas, ya que la octava la considera como una vuelta a la primera de ellas. El Padre de la Iglesia dice textualmente:

\footnotetext{
" Las siete primeras bienventuranzas son, en consecuencia, los grados de la vida perfecta. La octava muestra y esclarece la perfección alcanzada y, como si empezase de nuevo por la
}

${ }^{21}$ R. ÉTAIX, Ob. cit., pp. 395, 396, 398, 400, 401-404, 408 y $411-412$.

22 Obras Completas de San Agustín, Madrid, 1954, t. XII, pp. 774 y ss. 
primera, manifiesta que por estos grados todos los demás se perfeccionan"23.

Posteriormente, conduce esa vía de vida ejemplar hacia una compensación, y dice:

“...alegráos y regocijáos, porque es muy grande la recompensa que os aguarda en los cielos ..."

“... dijo en los cielos para designar las mansiones espirituales, donde mora la justicia eterna..."24.

Por lo tanto, a través de las normas dadas por Cristo, los bienaventurados que las sigan, en un trayecto no exento de dificultades, alcanzarán su triunfo que los conducirá al paraíso, a la Jerusalén celestial.

Por lo que se refiere a los otros textos, que servían como referente a clérigos $\mathrm{y}$ demás lectores medievales, hemos podido observar, en primer lugar, que en la homilía elegida de San León Magno, a propósito de las bienaventuranzas, se siguen muy de cerca las ideas del obispo de Hipona. Así, no sólo se afirma inicialmente que Cristo, en el Sermón de la Montaña, manifestó su doctrina, " para que los que desean llegar a la bienaventuranza eterna conozcan los grados de la felicísima subida", si no que en la exposición posterior se centra en comentar las siete primeras sentencias del sermón y elude la octava ${ }^{25}$. En esta línea hace, además, relaciones ideológicas entre la posesión de la tierra por los mansos y la carne de los santos, entre el bien de la justicia y el Señor o entre los limpios de corazón y la pureza de los ojos interiores, que tienen un clarísimo antecedente agustiniano ${ }^{26}$.

23 De Sermone Domini in Monte, capítulo III, 10.

${ }^{24}$ De Sermone Domini in Monte, capítulo V, 13.

25 San León Magno. Homilías sobre el año litúrgico, Madrid, 1969, p. 369.

${ }^{26}$ Ibidem, pp. 371-372 y 36.
En segundo lugar, el texto firmado por Beda el Venerable, que se extrajo del libro segundo de su In Lucae Evangelium Expositio, nos coloca ante un discurso en la línea de los precedentes ${ }^{27}$. En él se alude únicamente a cuatro de las bienaventuranzas, los pobres de espíritu..., los que tienen hambre y sed de justicia..., los que lloran...y los perseguidos...que se ponen en relación con las cuatro virtudes cardinales. Todo ello, con el fin de indicar al cristiano el camino correcto hacia la salvación, que el Venerable intentó dejar bien explícito, además, con citas muy significativas de salmos $\mathrm{u}$ otros pasajes bíblicos que señalan la felicidad del paraíso, lugar recuperado para los bienaventurados con la ayuda de Cristo.

Para terminar esta primera fase de estudio tenemos que aludir al Sermón 31 de San Agustín, que también está presente en las lecturas de estos mismos días. La homilía se pudo escuchar, en una festividad dedicada a ciertos mártires, antes del año 405 y en ella se comenta el salmo 125, 5-6 que dice:

“Los que siembran en lágrimas cosecharán en gozo. Al ir, iban llorando, arrojando la semilla; al volver vendrán cantando, trayendo sus gavillas" 28 .

Los comentarios del padre de la iglesia se orientaron a interpretar el fragmento como un símil de la vida humana en la que desde que se nace, llorando, se está en marcha, como un peregrino, de tribulación en tribulación, para llegar a la muerte que es el final del camino ${ }^{29}$.

En esta vía el que más llora es el justo, el santo, que así exige o celebra una buena obra y, claro está, quienes más siem-

27 P. L., 92, columnas, 401A-403D

28 Obras Completas de San Agustín, Madrid, 1981, t.VII, pp. $459-466$.

${ }^{29}$ Ibidem, p. 463. 
bren más recogerán, pues la tristeza y los dolores pasarán para alcanzar la alegría que no tiene fin. Incluso especifica que los santos disfrutarán de gozos eternos, pues pueden pedir al señor la recompensa prometi$\mathrm{da}^{30}$.

Esta exposición de San Agustín está muy en consonancia con la primera de las piezas citadas, De Sermone Domini in Monte, y se repiten los mismos sentidos simbólicos en ambas. Por lo tanto, hay una importante conjunción teórica entre todos los fragmentos que acabamos de tratar.

Una vez analizados estos cuatro textos, hemos continuado nuestra búsqueda a través de otros sermones de San Agustín donde el asunto de las bienaventuranzas está presente. Aunque, es conveniente puntualizar que los sermones número 53 y 53 A, dedicados completamente a las bienaventuranzas, no son objeto de copia en los homiliarios europeos hasta fechas avanzadas del siglo XII, por ello no son tratados en este trabajo ${ }^{31}$. Así, por ejemplo, aparecerán citados en el Leccionario Cartujo del manuscrito 33 de Grenoble y en el de SaintRémi de Reims, códice n⿳0 301(G), hoy en la biblioteca pública de la citada villa. Este último es un leccionario del oficio que copiaba el de Cluny de esa misma centuria ${ }^{32}$.

El nuevo grupo de sermones nos proporciona mayores precisiones para la explicación de las imágenes que decoran la arqueta $y$, en primer lugar, para las que se refieren a las figuras de los ángeles. En ellos se explicaban convenientemente estas representaciones, así, en el Sermón $n^{0}$ 6, al

${ }^{30}$ Ibidem, pp. 462-466

31 Obras Completas de San Agustín, t. X, p. 71-100. No obstante, no debemos descartar que dichos sermones formasen parte de recopilaciones que circulaban por la Península Ibérica y que hoy no conservamos, véase, M. C. DÍAZ Y DÍAZ, Códices visigóticos..., p. 231.

32 R. ÉTAIX, ob. cit, pp. 87, 90, 191-192 glosar la aparición de Dios a Moisés se dice textualmente:

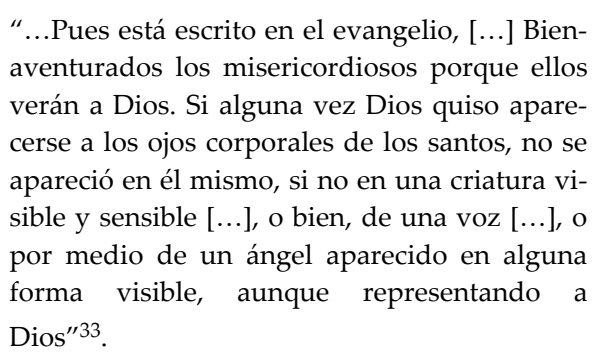
aventurados los misericordiosos porque ellos verán a Dios. Si alguna vez Dios quiso aparecerse a los ojos corporales de los santos, no se apareció en él mismo, si no en una criatura visible y sensible $[\ldots]$, o bien, de una voz $[\ldots]$, o por medio de un ángel aparecido en alguna forma visible, aunque representando a $\operatorname{Dios}^{\prime 3}$.

Este ángel es el mensajero, el nuncio que es enviado para comunicar algo $\mathrm{y}$, además,

“...Nuestros padres reconocían al Señor en sus
ángeles" ${ }^{34}$.

De este modo, la figura angélica, como voz del Señor, parece indicar al santo de la arqueta, a veces con gesto bien elocuente, señalando y mirando hacia lo alto, su destino hacia las moradas superiores (lámina 1). Pues, además, tal como especifica San Agustín en su Ciudad de Dios, dentro del

33 Obras Completas de San Agustín, t. VII, pp. 103104. Estas explicaciones sobre la función de los ángeles fueron ampliadas y divulgadas por San Gregorio Magno y San Isidoro de Sevilla en obras tan conocidas como las Homiliae in Evangelia o las Moralia in Job del primero, o los libros de las Sentencias o las Etimologías del segundo. Pero, además, se incluyeron el los homiliarios romanos, dentro de las fiestas dedicadas a los ángeles, véase, R. GRÉGOIRE, Les homéliaires..., p. 62 y del mismo autor Homéliaires liturgiques...pp. 180 y 343. Para la Península Ibérica, donde los homiliarios romanos no fueron tan copiados, en las fechas que nos interesan, el conocimiento de las obras citadas era general, pues así aparecen en las bibliotecas desde la época altomedieval, consúltese, M. C. DÍAZ Y DÍAZ, Códices visigóticos..., pp. 305, 306, 309, 310, 321-323, 334, 346, 354-355, 368, 385-387.

34 Obras Completas de San Agustín, t. VII, pp. 112,116, 193-197. En el Sermón no 7 sigue desarrollando esta idea al continuar con el asunto de la zarza que arde del Éxodo 3, 21-24 y en el Sermón no 12,también, pues glosa la cita de San Mateo 5, 8 referida a los bienaventurados limpios de corazón que verán a Dios. Interpretar a los ángeles de la arqueta como mensajeros, sin añadir ninguna fuente teórica, ya lo publicó, $\mathrm{H}$. STIERLING, "Ivoires de l'Espagne. Une grande tradition d'art somptuaire", L'oeil, 317 (1981) 46. 
libro XXII, el fin de dicha villa es la eterna felicidad de los santos, pues con ellos se llenarán las sillas que dejaron vacías los ángeles desertores ${ }^{35}$.

“...En aquella [ciudad] todos sus ciudadanos son inmortales, y los hombres llegarán a alcanzar lo que no perdieron nunca los ángeles santos" 36 .

Estas ideas fueron muy conocidas en los círculos eclesiásticos donde el texto agustiniano se manejaba abundantemente ${ }^{37}$. Pero, además, en Europa se leía esta obra con delectación en todo el periodo medieval $^{38}$.

Por otra parte, uno de los grandes difusores del pensamiento agustiniano, Cesáreo de Arles, retomó en su Sermón no 69 las enseñanzas del obispo africano que resumió y explicó de este modo tan elocuente:

\footnotetext{
"Hay dos ciudades carísimos hermanos: Una es la ciudad del mundo; otra, la ciudad del paraíso. En la ciudad del mundo el buen cristiano siempre es peregrino; en la ciudad del paraíso, siempre es ciudadano. Nuestra ciudad es la Jerusalén Celeste, nuestros ciudadanos son los ángeles; nuestros padres los patriarcas, profetas, apóstoles y mártires; nuestro Rey es Cristo" 39
}

De nuevo, el buen cristiano es visto como un peregrino en la tierra, pero alcanzará la ciudadanía en la urbe celestial donde ya se hallan los ángeles. Posiblemente, estos ángeles, en nuestra arqueta, además de comunicarle su destino, dan la bienve-

39 P.L., 39, 1877 y Obras Completas de San Agustín, t. XVI, p. 79*. En la Península Ibérica los sermones de Cesáreo de Arles fueron muy conocidos, en el llamado Homiliario de Toledo sus referencias son constantes, véase, R. GRÉGOIRE, Homéliaires liturgiques..., pp. 293319.
}

nida a la Jerusalén Celeste al bienaventurado que llega a ella (lámina 1).

Tras estas últimas pesquisas, la misma investigación nos condujo a la búsqueda, a través de otros sermones, de mayores precisiones para la explicación de las imágenes que decoran la caja y, en este caso, para las que se refieren a la representación de las figuras masculinas, nimbadas o no (lámina 1). En ciertas homilías leídas para celebrar las festividades de algunos mártires, santos o justos, nos hallamos ante numerosas aseveraciones que ahondan en la idea de que sus vidas eran modelos ejemplares.

En el Homiliario visigótico de la Biblioteca Británica, addit. ms. 30.853, que, según el profesor Díaz y Díaz, parece trasmitir una colección preparada en los últimos años de la monarquía hispanovisigoda, aunque éste sea un ejemplar del siglo XI, podemos seleccionar, entre un ingente catálogo de homilías agustinianas, las relativas a las festividades de San Vicente, San Esteban o de un desconocido Justo ${ }^{40}$. En ellas se habla del ejemplo de estos personajes que, a pesar de las tribulaciones han manifestado su rectitud, su mansedumbre y su amor a los enemigos. Por lo tanto, se cita textualmente, "no deben temer noticias tristes, pues van a estar como ángeles en el cielo" $^{\prime \prime 1}$.

${ }^{40}$ M. C. DíAZ y DíAZ, Códices visigóticos..., p. 317; R. GRÉGOIRE, Homéliaires liturgiques..., pp. 293-319. Parece que existió además un sermonario de San Agustín, usado por la iglesia altomedieval española, tal como Ambrosio de Morales vio en la biblioteca de San Salvador de Oviedo y recogió el profesor Díaz y Díaz en su obra Códices visigóticos..., p. 231 y donde posiblemente muchas de estas piezas dedicadas a los santos citados estarían presentes.

${ }^{41}$ R. GREGOIRE, Homéliaires liturgiques..., pp. 296, 305 y 314; Obras Completas de San Agustín, t. XXV, pp. 12-15 у C. LAMBOT "Sermons inédits de Saint Augustin pour des fêtes de Saint", Révue Bénédictine, LIX (1949) 59 y 75 . Sermones agustinianos donde estas mismas 
No hay duda, que las parejas de bienaventurados y ángeles que tenemos en el arca son seres susceptibles de ser emparejados y tratados con la misma dignidad. Así, estén santificados y porten nimbo o sean únicamente justos sin halo, todos ellos son los elegidos para una vida mejor (lámina 1).

Una vez analizadas las fuentes, podemos concluir que la arqueta primitiva debió estar formada por ocho plaquetas, cada una con el texto de una de las bienaventuranzas, según San Mateo 5, 3-10. Esta aseveración es posible ya que en las obras exegéticas citadas el resumen a siete bienaventuranzas se hace excluyendo la octava, los perseguidos por causa de la justicia..., que aquí está presente. Por lo tanto, podemos pensar que ha desaparecido o, no está localizada, la placa que contenía el texto de la cuarta sentencia del sermón de la montaña que versaba sobre aquellos que tienen hambre y sed de justicia...y que normalmente está presente, como hemos visto, en las glosas de los escritos patrísticos que hemos citado.

Por otra parte, pensamos que, como la mayoría de las obras escritas que sirven de base a la idea plástica, son bien conocidas en el occidente cristiano medieval, es muy difícil adscribir al mentor de la arqueta a un lugar determinado. No obstante, si, como se ha pensado hasta ahora, la pieza es española y del siglo XI, es muy fácil atribuir a un clérigo, buen conocedor de los textos aludidos, la idea iconográfica que plasmó el maestro tallista sobre las planchas de marfil. Pero además, si como puede conjeturarse, en la biblioteca real leonesa, heredera de la asturiana y enriquecida con obras llegadas del sur, no sería difícil en-

ideas están presentes los recoge el leccionario de oficio de Cluny, dentro de la parte dedicada al santoral, R: ÉTAIX, Homéliaires Patristiques..., pp. 153,159,163, 172, 200 y 205. contrar los sermonarios y obras de los padres citados, podemos ampliar el ámbito del patrocinio intelectual incluso al círculo de los monarcas de León, Fernando I y Sancha, quienes se cree que pagaron la obra.

Para finalizar, solo nos queda añadir que el tema es sumamente adecuado para ornar un contenedor de reliquias ${ }^{42}$. Los restos de los santos allí custodiados, ya que este es el uso que tuvo la obra hasta 1869 en que pasa al Museo Arqueológico Nacional, serían particularmente honrados en la festividad de todos los santos y fechas próximas, momentos en los que los textos que acabamos de referir eran leídos y glosados.

Es muy posible, por otra parte, que la pieza ocupase un lugar destacado en la basílica leonesa, junto a algunas otras del rico fondo isidoriano, y allí sus imágenes pudieron ser admiradas $\mathrm{y}$, por supuesto, perfectamente comprendidas por los ilustrados que se acercasen a venerar su contenido.

42 J. PÉReZ LlamaZARes, Ob. cit., p. 215 y J.A. HARRIS, The art of...., p. 254. 


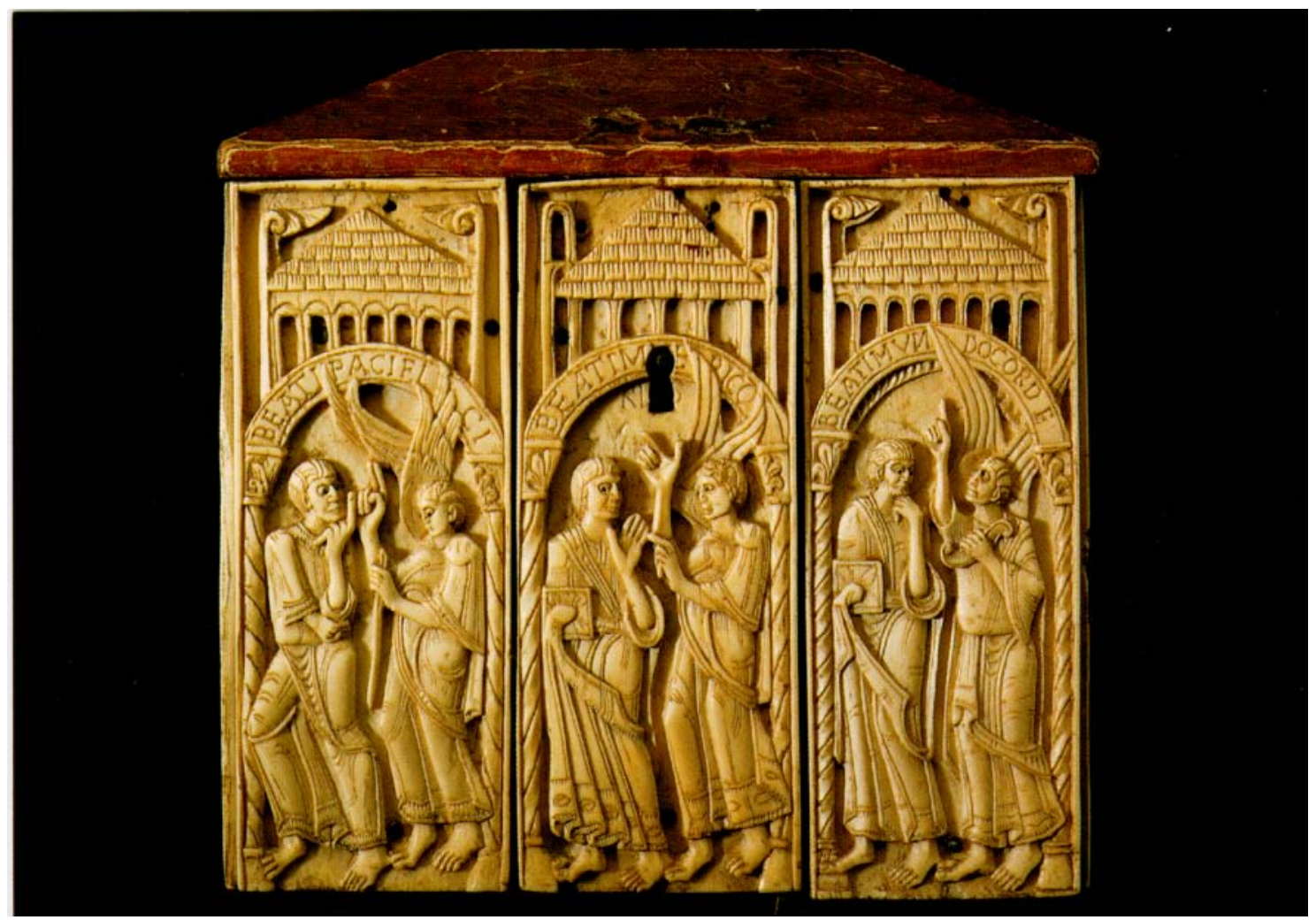

- Lám.1. Arqueta de las Buenaventuranzas. Museo Arqueológico Nacional, Madrid (Imagen del Museo Arqueológico y de AlDEASA, 1995. Fotografiada por E. Sáenz de San Pedro). 